Philosophische Untersuchungen

zur Theorie ästhetischer Erfahrung 
RALPH SZUKALA

\section{Philosophische Untersuchungen zur Theorie ästhetischer Erfahrung}


CIP-Titelaufnahme der Deutschen Bibliothek

Szukala, Ralph:

Philosophische Untersuchungen zur Theorie ästhetischer

Erfahrung / Ralph Szukala. - Stuttgart : Metzler, 1988

ISBN 978-3-476-00646-2

ISBN 978-3-476-00646-2

ISBN 978-3-476-03264-5 (eBook)

DOI 10.1007/978-3-476-03264-5

Dieses Werk einschließlich aller seiner Teile ist urheberrechtlich geschützt. Jede Verwertung außerhalb der engen Grenzen des Urheberrechtsgesetzes ist ohne Zustimmung des Verlages unzulässig und strafbar. Das gilt insbesondere für Vervielfältigungen, Übersetzungen, Mikroverfilmungen und die Einspeicherung und Verarbeitung in elektronischen Systemen.

(C) 1988 Springer-Verlag GmbH Deutschland

Ursprünglich erschienen bei J.B. Metzlersche Verlagsbuchhandlung und Carl Ernst Poeschel Verlag GmbH in Stuttgart 1988 
FÜR CLAUDIO 
INHALT

\author{
I Einleitung 7 \\ II Vieldeutigkeit, Unbestimmtheit, Negativität 17
}

III Das Problem der Fiktion 27

1. Irrealitätssetzung 27

2. Realität und Wirklichkeit, Wirklichkeit und Möglichkeit (I. Kant) 29

3. Fiktion, Phantasie und Neutralitätsmodifikation 34

IV Darstellungsfunktionen und ästhetische Valenz des literarischen Ausdrucks 44

$V$ Das Imaginäre (J.-P. Sartre) und das Ding der Wahrnehmung

(I. Kant, E. Husserl) 52

VI Die ästhetische Reflexion 99

1. Ästhetische Theorie der Negativität (Th.W. Adorno) 99

2. Zur Phänomenologie der literarischen Fiktion (R. Ingarden, W. Iser, J.-P. Sartre) 111

3. Ästhetische Idee und symbolische Hypotypose.

Die Bedeutung der Reflexion in der Ästhetik Kants 147

Literaturverzeichnis 174 